\title{
Distal Pancreatectomy
}

National Cancer Institute

\section{Source}

National Cancer Institute. Distal Pancreatectomy. NCI Thesaurus. Code C51647.

Surgical removal of the distal part of the pancreas. 